\title{
Surface treatment of silica nanoparticles for stable and charge-controlled colloidal silica
}

This article was published in the following Dove Press journal:

International Journal of Nanomedicine

15 December 2014

Number of times this article has been viewed

\section{Kyoung-Min Kim' \\ Hye Min Kim' \\ Won-Jae Lee ${ }^{2}$ \\ Chang-Woo Lee $^{3}$ \\ Tae-il Kim ${ }^{4}$ \\ Jong-Kwon Lee ${ }^{5}$ \\ Jayoung Jeong ${ }^{5}$ \\ Seung-Min Paek ${ }^{2}$ \\ Jae-Min $\mathrm{Oh}^{\prime}$}

'Department of Chemistry and Medical Chemistry, College of Science and Technology, Yonsei University,

Gangwon-do, Republic of Korea;

${ }^{2}$ Department of Chemistry, Kyungpook

National University, Taegu, Republic

of Korea; ${ }^{3}$ Battelle-Korea Laboratory,

International Center for Converging

Technology, Korea University, Seoul,

Republic of Korea; ${ }^{4}$ Department

of Biosystems and Biomaterials

Science and Engineering, College

of Agriculture and Life Sciences,

Seoul National University, Seoul,

Republic of Korea; ${ }^{5}$ Toxicological

Research Division, National Institute

of Food and Drug Safety Evaluation,

Chungchungbuk-do, Republic of Korea

Correspondence: Jae-Min Oh

Department of Chemistry and

Medical Chemistry, College of Science

and Technology, Yonsei University,

Gangwon-do 220-7I0, Republic of Korea

Tel +82 337602368

Fax +82337602182

Email jaemin.oh@yonsei.ac.kr

Seung-Min Paek

Department of Chemistry, Kyungpook

National University, Taegu 702-70I,

Republic of Korea

Tel +8253950 5335

Fax +82539506330

Emailsmpaek@knu.ac.kr
Abstract: An attempt was made to control the surface charge of colloidal silica nanoparticles with $20 \mathrm{~nm}$ and $100 \mathrm{~nm}$ diameters. Untreated silica nanoparticles were determined to be highly negatively charged and have stable hydrodynamic sizes in a wide $\mathrm{pH}$ range. To change the surface to a positively charged form, various coating agents, such as amine containing molecules, multivalent metal cation, or amino acids, were used to treat the colloidal silica nanoparticles. Molecules with chelating amine sites were determined to have high affinity with the silica surface to make agglomerations or gel-like networks. Amino acid coatings resulted in relatively stable silica colloids with a modified surface charge. Three amino acid moiety coatings (L-serine, L-histidine, and L-arginine) exhibited surface charge modifying efficacy of L-histidine $>$ L-arginine $>$ L-serine and hydrodynamic size preservation efficacy of L-serine $>$ L-arginine $>$ L-histidine. The time dependent change in L-arginine coated colloidal silica was investigated by measuring the pattern of the backscattered light in a Turbiscan ${ }^{\mathrm{TM}}$. The results indicated that both the $20 \mathrm{~nm}$ and $100 \mathrm{~nm}$ L-arginine coated silica samples were fairly stable in terms of colloidal homogeneity, showing only slight coalescence and sedimentation.

Keywords: silica, nanoparticles, surface charge, colloidal stability, turbidity, amino acids

\section{Introduction}

After the launch of the National Nanotechnology Initiative in 2000 in the United States, many scientists and engineers have engineered nanomaterials with surprising and controllable physicochemical characters. ${ }^{1}$ Quantum dot nanoparticles such as $\mathrm{CdSe}$ and $\mathrm{ZnSe}$ nanoparticles are luminescent materials with strong and controllable fluorescence. ${ }^{2}$ Layered nanoparticles, like nanoclays, have been reported to have potential as cellular drug delivery carriers. ${ }^{3}$ Gold or platinum nanoparticles have been utilized for photothermal therapeutics or X-ray computed tomography contrast agents. ${ }^{4,5}$ Iron oxide nanoparticles serve as sensitive magnetic resonance image contrast agents with unexpected efficacy. ${ }^{6-9}$ Nanosized carbon materials such as carbon black, carbon nanotubes, and graphene are being developed as energy storage materials. ${ }^{10} \mathrm{TiO}_{2}$ nanoparticles are being produced as semiconductors with photocatalytic effects. ${ }^{11,12} \mathrm{ZnO}$ nanoparticles are included in personal care products due to their ultraviolet absorbency. ${ }^{13,14} \mathrm{SiO}_{2}$ (silica) nanoparticles are being utilized in a wide range of industrial applications, including as thickening agents, desiccants, toothpaste additives, and adsorbents. ${ }^{15-18}$ With the increase in the demand for and production of nanomaterials, the general public will have a higher possibility of being exposed to engineered nanomaterials. Thus, the Working Party on Manufactured Nanomaterials (WPMN) of the Organization for Economic Cooperation 
and Development (OECD) selected 14 nanomaterials to analyze for potential human health risks. ${ }^{19}$

Health risk assessment is the process of finding the physicochemical parameters of nanomaterials that adversely affect biological behaviors. Understanding the properties and preparing standard samples of nanoparticles are key steps in an evaluation for toxicity. Already, the WPMN of the OECD has suggested a guideline for the environmental toxicity evaluation of nanoparticles, and parameters such as the properties of the as-produced powder nanoparticles (size, size distribution, shape, crystallinity, crystal structure, chemical composition and purity, surface chemistry, surface reactivity, and specific surface area) and the properties of nanoparticles in liquid suspension (size distribution, surface charge, solubility, surface activity, sedimentation, fluorescence, and protein corona), were demonstrated. ${ }^{19}$ Generally, the characteristics of nanoparticles come from their very small size and relatively large surface area, and the reactive chemical properties of their surfaces. Such characteristics are related to interparticle interactions, like agglomeration or flocculation. There is a need to prepare samples in which the particle size and aforementioned properties are independently controlled for accurate biological analysis of nanoparticles.

More recent studies have been interested in the surface property of nanosilica suspension for biological evaluation of nanoparticles. Functionalization of nanosilica suspensions (starting from powdered nanosilica) by various agents has been investigated for toxicological evaluation, and their colloidal stability has been studied in either physiological media or biomimetic conditions. ${ }^{20-22}$ Orts-Gil et al and Natte et al reported that the surface charge and hydrodynamic size of silica nanoparticles (Ludox TM50, Cat Number: 420778; Sigma-Aldrich Co., LLC, St Louis, MO, USA), changed depending on the concentration of ionic species, and that the silica nanoparticles with highly negative surface charge had colloidal stability at neutral or basic $\mathrm{pH} \cdot{ }^{20,23}$

Industrial interests lie in two production classes for silica-based nanomaterials: fumed and colloidal. ${ }^{18,24-26}$ In our current study, the colloidal silica nanoparticles starting from as-prepared silica colloid were functionalized and characterized in terms of size, surface charge, and particle homogeneity to provide standardized samples for toxicological studies. As suggested by the WPMN's guideline, the standardization of nanomaterials is of prime importance for precise evaluation of nanotoxicity. We mainly concentrated our efforts on the preparation of standard silica nanoparticles having well defined physicochemical properties for toxicity evaluation. Two specific parameters, particle size and surface charge, were independently controlled. Commercially available colloidal silica nanoparticles with $20 \mathrm{~nm}$ and $100 \mathrm{~nm}$ diameters were chosen as the primary particles. As the highly well dispersed colloidal silica nanoparticles are easily destabilized by additional treatment with chemicals, it is not a simple task to control only the surface charge without affecting the other colloidal properties. $^{24,27-32}$ Therefore, in this work, the simplest way of coating was applied to keep the other physicochemical properties unchanged. Considering the strong negative surface charge of silica, cationic coating agents were tested: amine containing molecules, multivalent metal cation, and basic amino acids. The changes in the zeta potential and hydrodynamic size upon coating with various materials were investigated under a variety of coating conditions, including reaction ratios with silica and coating agent concentration, gelation time, and $\mathrm{pH}$. The time dependent turbidity change was also monitored to observe the change in the colloidal homogeneity upon amino acid coating. Consequently, optimum conditions for preparing standard silica nanoparticle samples with independently controlled particle size and surface charge are suggested herein.

\section{Material and methods Materials}

The colloidal silica nanoparticle (30.4 weight/volume [wt/v] $\%$ in deionized [DI] water) suspension with $20 \mathrm{~nm}$ (Cat No: NPS-SOL 20) and $100 \mathrm{~nm}$ (Cat No: NPS-SOL 100) diameter sizes were purchased from E\&B Nanotech Co, Ltd (Ausan, Gyeonggi-do, South Korea) and are abbreviated as $\mathrm{SiO}_{2}$ EN20(-) and $\mathrm{SiO}_{2}{ }^{\mathrm{EN} 100(-)}$, respectively. The EUDRAGIT ${ }^{\circledR}$ E-100 was purchased from Evonik Industries (Essen, Germany). The aluminum chloride hexahydrate (Cat No: 237078), ethylenediamine ([EDA] Cat No: 240729), tris(2-aminoethyl)amine ([TAEA] Cat No: 225630), 3-aminopropyltriethoxysilane ([APTES] Cat No: A3648), L-serine ([L-ser] Cat No: S4311), L-histidine ([L-his] Cat No: H8000), and L-arginine ([L-arg] Cat No: A5006) were purchased from Sigma Aldrich Co., LLC. Hydrochloric acid ([HCl] Cat No: 1129) and sodium hydroxide ([NaOH] Cat No: 7570-4400) were supplied by DUKSAN Co., Ltd (South Korea) and Daejung Chemicals and Metals Co., Ltd (South Korea), respectively.

\section{Characterization of the colloidal silica nanoparticles}

To determine the zeta potentials and hydrodynamic sizes of $\mathrm{SiO}_{2}^{\mathrm{EN} 20(-)}$ and $\mathrm{SiO}_{2}^{\mathrm{EN} 100(-)}$, as purchased colloidal silicas $(30.4 \mathrm{wt} / \mathrm{v} \%)$ were diluted with DI water until $2.5-5 \mathrm{wt} / \mathrm{v} \%$. The $\mathrm{pH}$ dependent surface charges and hydrodynamic sizes were determined using a zeta potential and particle size analyzer 
ELSZ-1000 (Otsuka Electronics Co., Ltd, Osaka, Japan). A few drops of diluted $\mathrm{HCl}(1 \mathrm{~mol} / \mathrm{L})$ and $\mathrm{NaOH}$ solution $(1 \mathrm{~mol} / \mathrm{L})$ were utilized to adjust the $\mathrm{pH}$ of the suspension.

\section{Surface treatment of the colloidal silica with various coating reagents}

Both $\mathrm{SiO}_{2}{ }^{\mathrm{EN} 20(-)}$ and $\mathrm{SiO}_{2}^{\mathrm{EN} 100(-)}$ with $30.4 \mathrm{wt} / \mathrm{v} \%$ concentrations were diluted to various concentrations using DI water. For surface coating, the diluted colloidal silica nanoparticles were mixed with various coating reagents, such as EUDRAGIT $^{\circledR}$ E-100, Al(III) solution, EDA, TAEA, APTES, L-ser, L-his, and L-arg, and were then vigorously stirred at room temperature for 1 hour. The mixed samples were continuously titrated until the final $\mathrm{pH}$ reached 6.5, 6.0, and 5.5. The colloidal stability of the coated samples was evaluated by measuring time to gelation after coating. All the coated samples in a $50 \mathrm{~mL}$ conical tube were gently swirled to check gelation at 1, 2, 6, 12, 24, and 48 hour intervals.

\section{Surface charge control of colloidal silica utilizing amino acids}

Pristine $30.4 \mathrm{wt} / \mathrm{v} \% \mathrm{SiO}_{2}{ }^{\mathrm{EN} 20(-)}$ and $\mathrm{SiO}_{2}{ }^{\mathrm{EN} 100(-)}$ colloidal silica nanoparticles were diluted to $10.2 \mathrm{wt} / \mathrm{v} \%$ using DI water. To modify the surfaces of the colloidal silica nanoparticles, $10.1 \mathrm{wt} / \mathrm{v} \%, 100 \mathrm{~mL}$ colloidal silica was mixed with 3 or 10 $\mathrm{wt} / \mathrm{v} \%$ L-ser, L-his, and L-arg solutions in a $500 \mathrm{~mL}$ beaker, and then the mixed samples were vigorously stirred at around $298 \mathrm{~K}$ for 1 hour. The mixed samples were titrated with an $\mathrm{HCl}$ solution with different concentrations $(0.1 \mathrm{M}, 0.15 \mathrm{M}$, and $0.2 \mathrm{M}$ ) until $\mathrm{pH}$ 6.5, 6.0, and 5.5, respectively. These surface charge controlled colloidal silica nanoparticles are abbreviated as $\mathrm{SiO}_{2}{ }^{\mathrm{EN} 20(\mathrm{~S})}, \mathrm{SiO}_{2}{ }^{\mathrm{EN} 100(\mathrm{~S})}, \mathrm{SiO}_{2}{ }^{\mathrm{EN} 20(\mathrm{H})}, \mathrm{SiO}_{2}{ }^{\mathrm{EN} 100(\mathrm{H})}$, $\mathrm{SiO}_{2}{ }^{\mathrm{EN} 20(\mathrm{R})}$, and $\mathrm{SiO}_{2}{ }^{\mathrm{EN} 100(\mathrm{R})}$, respectively, in this study.

The surface charge and colloidal stability were evaluated by zeta potentials and hydrodynamic sizes at $0.5,2,6$, 24 , and 48 hours after coating. The mean zeta potential and hydrodynamic size of the surface coated silica samples were measured with the ELSZ-1000 using zeta flow cells (Otsuka Electronics Co., Ltd.) and dynamic light scattering (DLS) disposable cuvettes (Ratiolab GmbH, Dreieich, Germany; Cat No: 2811110), and were then automatically calculated using the Smoluchowski and Contin method. The refractive indices of water and silica were 1.330 and 1.440 , respectively. The values and distributions of zeta potential and hydrodynamic size were determined by ELSZ v3 software (Otsuka Electronics Co., Ltd.). The results of the zeta potential were selected when the zeta potential distributions according to the height in cuvette were parabolic from its center and, at the same time, the difference between upper and lower value was under $40 \mathrm{mV}$. The results of hydrodynamic size were selected by 100 accumulated results reported by software, which showed OK sign. The particle migration and size variation of $\mathrm{SiO}_{2}{ }^{\mathrm{EN} 20(\mathrm{R})}$ and $\mathrm{SiO}_{2}{ }^{\mathrm{EN} 100(\mathrm{R})}$ were determined with Turbiscan ${ }^{\mathrm{TM}}$ Lab (Formulaction Inc., Davie, FL, USA), using a near infrared light source. The detection head scanned the entire height of the cell $(55 \mathrm{~mm})$ at $298 \mathrm{~K}$ every 1.5 hours during a 48 hour period, acquiring transmission and backscattering every $40 \mu \mathrm{m}$.

\section{Results \\ Characterization of the colloidal silica nanoparticles}

The colloidal properties (eg, zeta potential, hydrodynamic size) of the as purchased colloidal silica nanoparticles are shown in Figure 1. $\mathrm{SiO}_{2}{ }^{\mathrm{EN} 20(-)}$ and $\mathrm{SiO}_{2}{ }^{\mathrm{EN} 100(-)}$, which were advertised to have average diameters of $20 \mathrm{~nm}$ and $100 \mathrm{~nm}$, in fact, exhibited hydrodynamic sizes of approximately $23 \mathrm{~nm}$ and approximately $93 \mathrm{~nm}$, respectively (Figure 1A). These results corresponded well with the previously reported primary particle size of the same silica nanoparticles observed via scanning electron microscopy and transmission electron microscopy ${ }^{26}$ It is worth noting that this hydrodynamic size was maintained in the 3-13 $\mathrm{pH}$ range, suggesting that the colloidal stability of both silica nanoparticles was retained regardless of the $\mathrm{pH}$ value. Figure $1 \mathrm{C}$ shows the hydrodynamic size distribution of colloidal silica at a neutral $\mathrm{pH}$ (approximately 7) according to the intensity distribution pattern, showing a fairly narrow distribution with homogeneous sizes. The zeta potential of both the 20 and $100 \mathrm{~nm}$ colloidal silica nanoparticles showed a highly negative charge in the 3-13 $\mathrm{pH}$ range. Like most other nanoparticle colloids, the current colloidal silica nanoparticles exhibited $\mathrm{pH}$ dependent zeta potential values; the higher the $\mathrm{pH}$, the more negative the zeta potential values. The zeta potential values of both $\mathrm{SiO}_{2}{ }^{\mathrm{EN} 20(-)}$ and $\mathrm{SiO}_{2}{ }^{\mathrm{EN} 100(-)}$ were maintained at $-40 \mathrm{mV}$ and $-50 \mathrm{mV}$, respectively, in the $6-10 \mathrm{pH}$ range. The zeta potential values at $\mathrm{pH} 7$ (Figure 1D) had narrow distributions, and all the particles were determined to have negative surface charges.

\section{Stability of colloidal silica under various kinds of coating reagents having positive charges}

To modify the surface charge of colloidal silica while maintaining particle size, coating experiments with various molecules were conducted (Figure 2), using established 
A

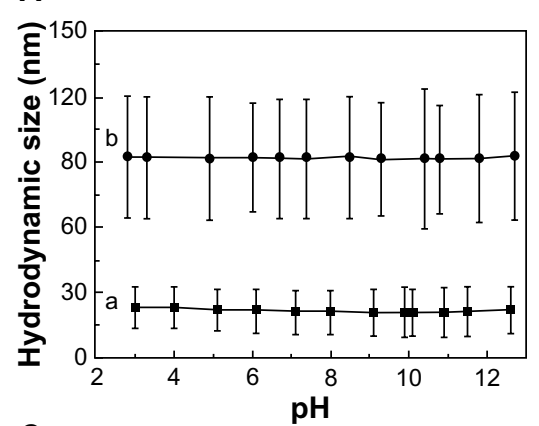

C

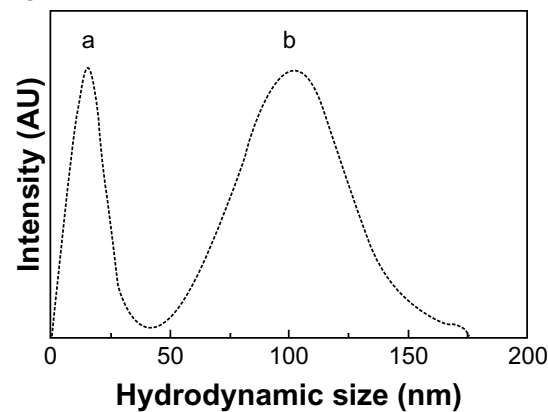

B

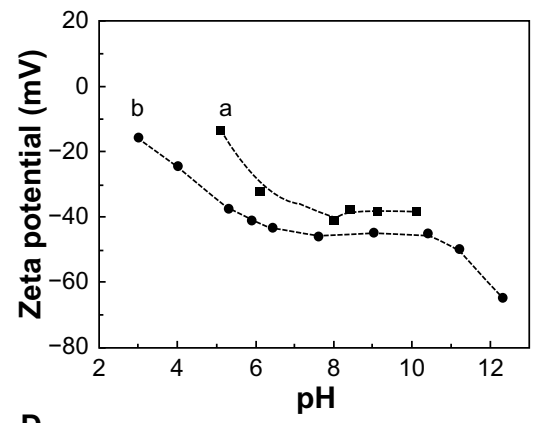

D

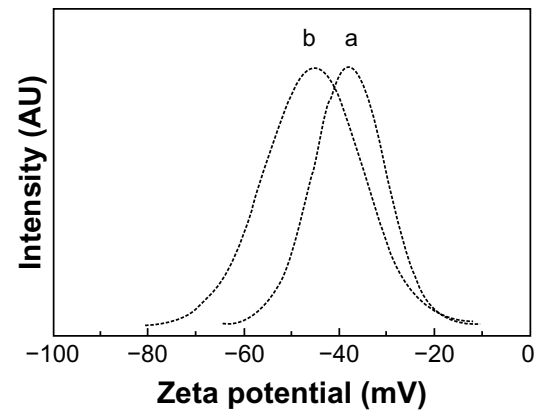

Figure I Properties of colloidal silica nanoparticle suspension.

Notes: (A) Hydrodynamic size, (B) zeta potential depending on the $\mathrm{pH}$ of deionized water, (C) hydrodynamic size, and (D) zeta potential at $\mathrm{pH} 7.0 \pm 0.4$ in deionized water for colloidal silica nanoparticle suspension with (a) $20 \mathrm{~nm}$ diameter and (b) $100 \mathrm{~nm}$ diameter. Errors bars are based on polydispersity index.

EDA

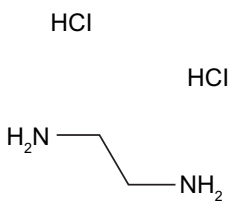

TAEA

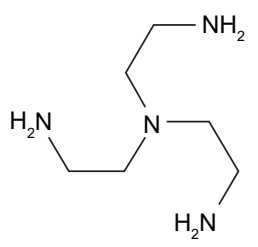

APTES<smiles>CCO[Si](CCCN)(OCC)OCC</smiles>

Aluminum chloride

$$
\mathrm{AlCl}_{3} \cdot 6 \mathrm{H}_{2} \mathrm{O}
$$

Eudragit ${ }^{\circledR}$ E-100<smiles>CCOC(=O)C(C)(CC(C)(C)CC(C)(C)C(=O)OCCN(C)C)C(=O)OC</smiles>

L-serine<smiles>N[C@@H](CO)C(=O)O</smiles>

L-histidine<smiles>NC(Cc1c[nH]cn1)C(=O)O</smiles>

L-arginine<smiles>N=C(N)NCCC[C@H](N)C(=O)O</smiles>

Figure 2 Chemical formula and positively charged groups of various coating reagents.

Note: EUDRAGIT ${ }^{\circledR}$ E-100, Evonik Industries, Essen, Germany.

Abbreviations: APTES, 3-aminopropyltriethoxysilane; EDA, ethylenediamine; TAEA, tris(2-aminoethyl)amine. 
methodologies. ${ }^{26,33}$ Four different categories of coating reagents were utilized: amine containing molecules, multivalent metal cation, cationic polymers, and basic amino acids. All the coating agents had cationic centers to modify the highly negative surface charge of the silica nanoparticles. For the first step, the formation of gels that attributed to the strong interaction between the nanoparticles and the coating reagents were examined as the gelation indicated that the colloid had lost its stability. ${ }^{20}$ The results are summarized in Table 1. The degree of gelation was evaluated as the time required for complete gel formation after the addition of the coating agent to the colloidal silica while stirring. We determined that there was gelation when the inner substance of the colloid did not flow upon turning the container upside down. EDA, a divalent amine chelate, showed concentration dependent gelation upon mixing with colloidal silica, exhibiting immediate gelation in a high EDA concentration. TAEA, a tetravalent amine chelate, resulted in relatively rapid gelation compared with EDA, resulting in an immediate gelation even at a very low concentration $(0.03 \mathrm{wt} / \mathrm{v} \%)$. The APTES reagent, which together had an amine and silane moiety, also resulted in gelation within 2 hours. The gelation of colloidal silica was more accelerated with the multivalent metal cation $\mathrm{Al}^{3+}$, showing immediate gelation at a very low concentration (0.01 wt/v\%). EUDRAGIT ${ }^{\circledR}$ E-100, a methacrylate based copolymer generally utilized for medical purposes, also showed gradual gelation when mixed with colloidal silica.
Basic amino acids like L-ser, L-his, and L-arg also showed gelation according to increasing concentrations of silica and amino acids. Optimal conditions for amino acid coating were found by adjusting the concentrations and reaction ratios and observing the degree or absence of coagulation over a 48 hour period. The $3-10 \mathrm{wt} / \mathrm{v} \%$ colloidal silica samples maintained their sol-like colloidal states with the addition of $0.3-1.0 \mathrm{wt} / \mathrm{v} \%$ amino acids. The result shown in Table 1 is for $\mathrm{SiO}_{2}{ }^{\mathrm{EN} 20(-)}$, but a similar gelation pattern was obtained with $\mathrm{SiO}_{2}^{\mathrm{EN} 100(-)}$.

\section{Colloidal properties of amino acid coated colloidal silica}

As it had been verified that the amino acids, as coating reagents, can modify the surface of colloidal silica while maintaining the sol stability, the zeta potential and hydrodynamic size change of silica upon coating was measured in detail. As the $\mathrm{pH}$ value affected the ionic form of the amino acids as well as the surface charges of the silica nanoparticles, the time dependent zeta potential and hydrodynamic size changes were evaluated for 48 hours with respect to three different $\mathrm{pH}$ values: 5.5, 6.0, and 6.5.

Figure 3 represents the time- and $\mathrm{pH}$-dependent changes in the zeta potentials and hydrodynamic sizes of $\mathrm{SiO}_{2}{ }^{\mathrm{EN} 20(\mathrm{~S})}$ and $\mathrm{SiO}_{2}{ }^{\mathrm{EN} 100(\mathrm{~S})}$. At $\mathrm{pH} 5.5$, the $20 \mathrm{~nm}$ colloidal silica showed no significant change in its zeta potential. On the other hand, the zeta potential value increased by approximately $10 \mathrm{mV}$

Table I Surface charge and colloidal stability of the colloidal silica with various coating agents in the 5.5-6.5 pH range

\begin{tabular}{|c|c|c|c|c|}
\hline \multicolumn{2}{|l|}{ Coating reagents } & \multirow{2}{*}{$\begin{array}{l}\mathrm{SiO}_{2} \text { content } \\
(\mathrm{wt} / \mathrm{v} \%)\end{array}$} & \multirow{2}{*}{$\begin{array}{l}\text { Reagents content } \\
\text { (wt/v\%) }\end{array}$} & \multirow[t]{2}{*}{ Gelation } \\
\hline Category & Chemical name & & & \\
\hline \multirow[t]{5}{*}{ Amine containing molecules } & EDA & $10-20$ & $0.03,0.06,0.09$ & + \\
\hline & & & $0.12,0.15$ & ++ \\
\hline & & & $0.18,0.3,0.6,0.9,1.2,1.8$ & +++ \\
\hline & TAEA & $10-20$ & $0.03,0.06,0.3,0.6,3,6$ & +++ \\
\hline & APTES & $10-30$ & $0.3,0.6,0.9,1.2,1.5$ & ++ \\
\hline \multirow[t]{2}{*}{ Multivalent metal cation } & $\mathrm{Al}(\mathrm{III})$ solution & $10-30$ & $1.0 \times 10^{-3}, 2.0 \times 10^{-3}, 4.0 \times 10^{-3}, 8.0 \times 10^{-3}$ & ++ \\
\hline & & & $1.0 \times 10^{-2}, 2.0 \times 10^{-2}, 4.0 \times 10^{-2}$ & +++ \\
\hline Cationic polymer & Eudragit $^{\circledR}$ E-I00 & $10-20$ & $0.1,0.2,0.4,0.8$ & ++ \\
\hline \multirow[t]{10}{*}{ Amino acids } & L-serine & $3-10$ & $0.3,0.6,0.9,1.2,1.5,1.8,2.1$ & - \\
\hline & & & $2.4,2.7,3.0$ & + \\
\hline & L-histidine & $3-10$ & $0.3,0.6,0.9,1.2$ & - \\
\hline & & & I.5, I.8, 2.I, 2.4, 2.7, 3.0 & + \\
\hline & L-arginine & $3-10$ & $0.3,0.6$ & - \\
\hline & & & $0.9,1.2,1.5,1.8$ & + \\
\hline & & & $2.1,2.4,2.7,3.0$ & ++ \\
\hline & & $10-20$ & $0.3,0.6,0.9,1.2,1.5$ & + \\
\hline & & & I.8, 2.I, $2.4,2.7$ & ++ \\
\hline & & & 3.0 & +++ \\
\hline
\end{tabular}

Notes: -, no gelation within 48 h; +, gelation within 24 h; ++, gelation within 2 h; +++, immediate gelation. EUDRAGIT ${ }^{\circledR}$ E-I00, Evonik Industries, Essen, Germany. Abbreviations: APTES, 3-aminopropyltriethoxysilane; EDA, ethylenediamine; TAEA, tris(2-aminoethyl)amine; h, hours; wt/v, weight/volume. 

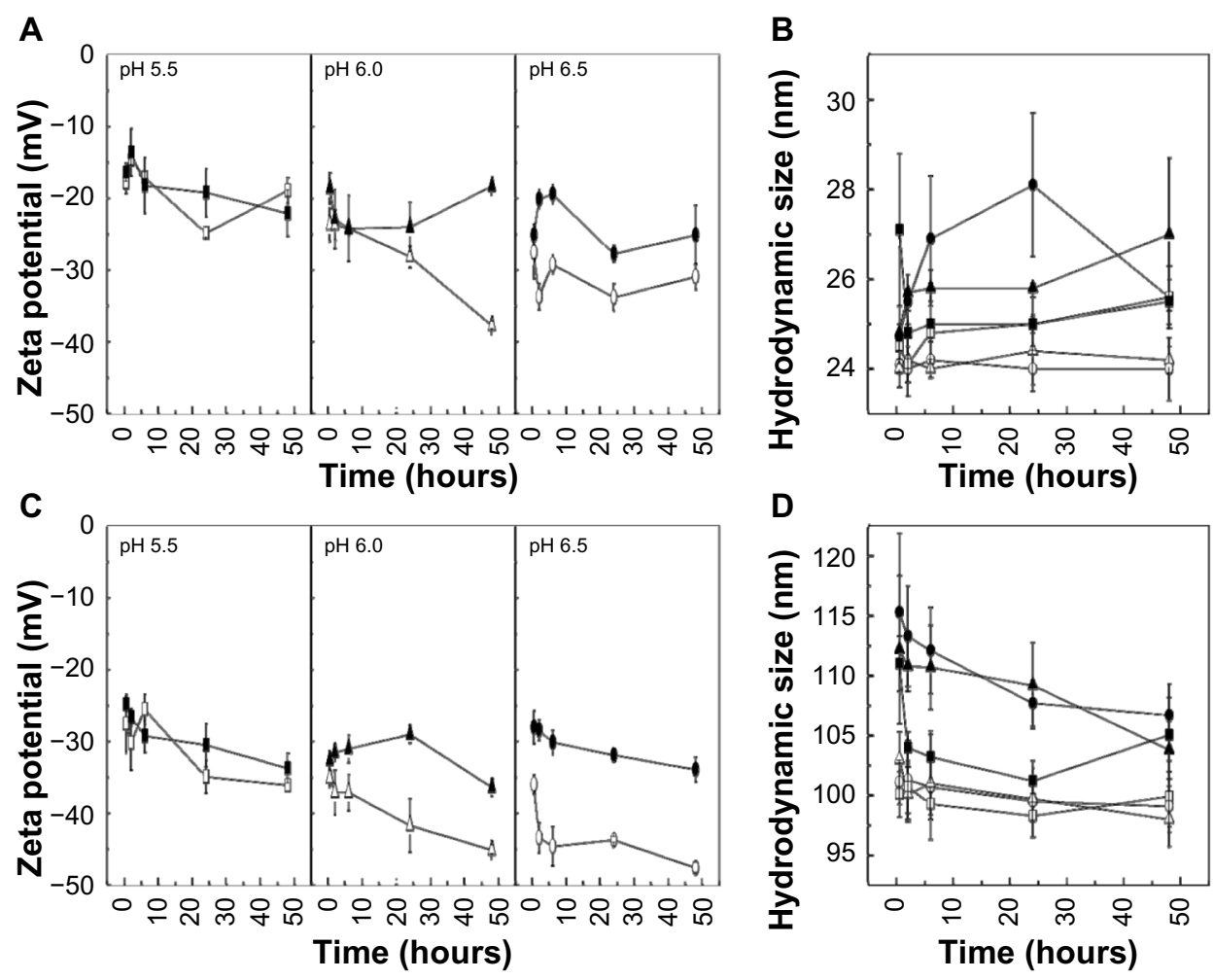

Figure 3 Zeta potential and hydrodynamic size of silica nanoparticles coated with L-serine.

Notes: (A) Zeta potential of colloidal silica nanoparticles with $20 \mathrm{~nm}$ diameter, (B) hydrodynamic size of colloidal silica nanoparticles with $20 \mathrm{~nm}$ diameter, (C) zeta potential of colloidal silica nanoparticles with $100 \mathrm{~nm}$ diameter, and (D) hydrodynamic size of colloidal silica nanoparticles with $100 \mathrm{~nm}$ diameter at pH 5.5, 6.0, and 6.5, and pristine silica depending on the time, respectively. Open or solid squares/triangles/circles represent L-serine coated or uncoated samples at $\mathrm{pH} 5.5,6.0$, and 6.5 , respectively.

upon L-ser treatment in pH 6.0 and 6.5 (Figure 3A). Although the overall maximum hydrodynamic size increased to $28 \mathrm{~nm}$ at $\mathrm{pH} 6.5$, no serious agglomeration or aggregation was observed. The average hydrodynamic size of the $20 \mathrm{~nm}$ silica was maintained at approximately $25 \mathrm{~nm}$ across the $\mathrm{pH}$ range. The $100 \mathrm{~nm}$ colloidal silica also showed a similar pattern in terms of the zeta potential and hydrodynamic size. At pH 5.5, the zeta potential value was not significantly changed after coating while approximately 10 and $15 \mathrm{mV}$ zeta potential increases were observed at $\mathrm{pH} 6.0$ and 6.5, respectively. The hydrodynamic size showed a slight increase from approximately $95 \mathrm{~nm}$ (uncoated) to $110-115 \mathrm{~nm}$ right after the coating reaction, but the hydrodynamic size gradually recovered its original value with increasing time, suggesting that the L-ser coated $\mathrm{SiO}_{2}{ }^{\mathrm{EN} 100(-)}$ restored its colloidal stability.

The time dependent zeta potentials and hydrodynamic sizes of $\mathrm{SiO}_{2}{ }^{\mathrm{EN} 20(\mathrm{H})}$ and $\mathrm{SiO}_{2}{ }^{\mathrm{EN} 100(\mathrm{H})}$ are shown in Figure 4. Experiments were also carried out with three different $\mathrm{pH}$ values: 5.5, 6.0, and 6.5. The $20 \mathrm{~nm}$ colloidal silica showed a significant increase in zeta potential at all the $\mathrm{pH}$ conditions tested (Figure 4A). The zeta potential increased to approximately 15,20 , and $15 \mathrm{mV}$ at the $5.5,6.0$, and 6.5 $\mathrm{pH}$ conditions, respectively. The zeta potential increase was larger compared with that in the L-ser coated colloidal silica. Figure 4B shows that the hydrodynamic size clearly increased with time after L-his coating. While the average size before coating was approximately $25 \mathrm{~nm}$ regardless of $\mathrm{pH}$, the hydrodynamic size increased after L-his coating, resulting

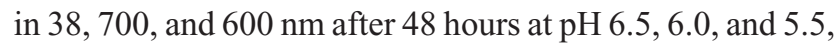
respectively. It is worth noting that the hydrodynamic size of $\mathrm{SiO}_{2}^{\mathrm{EN} 20(\mathrm{H})}$ increased more than 30-fold at $\mathrm{pH} 6.0$ and 6.5, suggesting the formation of large agglomerates. Similar to the $20 \mathrm{~nm}$ silica, the $100 \mathrm{~nm}$ silica showed a similar pattern in the zeta potential and hydrodynamic size with the L-his coating. The zeta potential of $\mathrm{SiO}_{2}{ }^{\mathrm{EN} 100(\mathrm{H})}$ significantly increased after L-his coating (Figure 4C). The average differences in the zeta potential before and after coating were approximately 20, 25, and $20 \mathrm{mV}$ for $\mathrm{pH} 5.5,6.0$, and 6.5, respectively. The hydrodynamic size of the $100 \mathrm{~nm}$ colloidal silica did not show a serious increase after L-his coating compared with the $20 \mathrm{~nm}$ silica, but $\mathrm{SiO}_{2}{ }^{\mathrm{EN} 100(\mathrm{H})}$ exhibited more than 20 -fold $(>400 \mathrm{~nm})$ size increase at $\mathrm{pH} 5.5$, which was a relatively high degree of agglomeration compared with L-ser coating.

Figure 5 displays the time dependent zeta potential and hydrodynamic size changes of $\mathrm{SiO}_{2}{ }^{\mathrm{EN} 20(\mathrm{R})}$ and $\mathrm{SiO}_{2}{ }^{\mathrm{EN} 100(\mathrm{R})}$ with respect to the $\mathrm{pH}$ condition. The $20 \mathrm{~nm}$ colloidal silica 
A

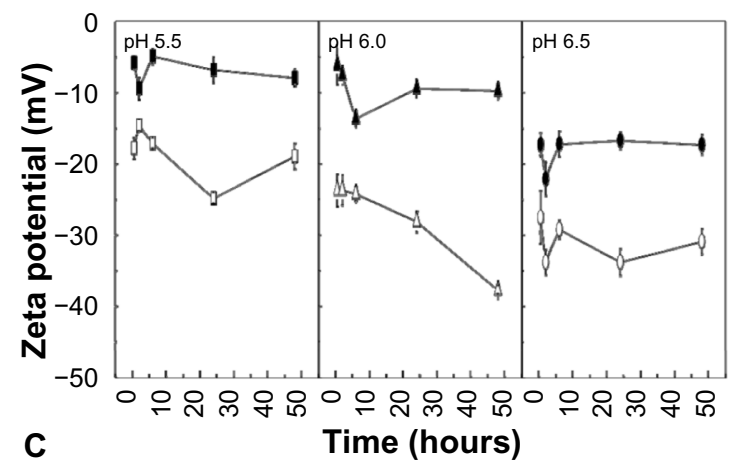

C

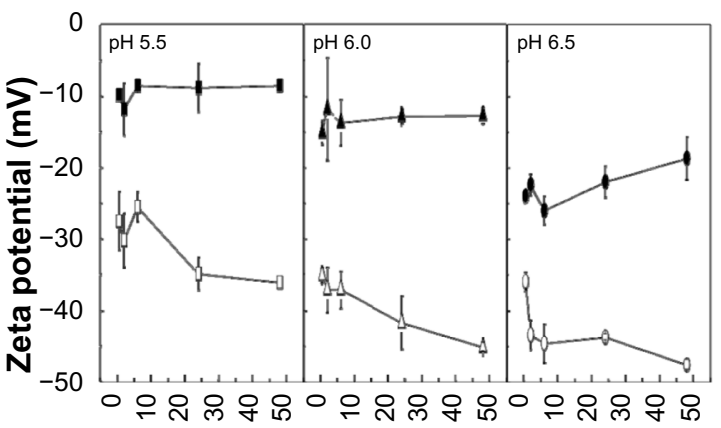

Time (hours)

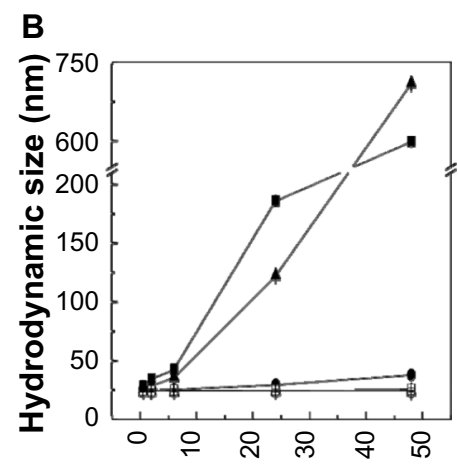

D Time (hours)

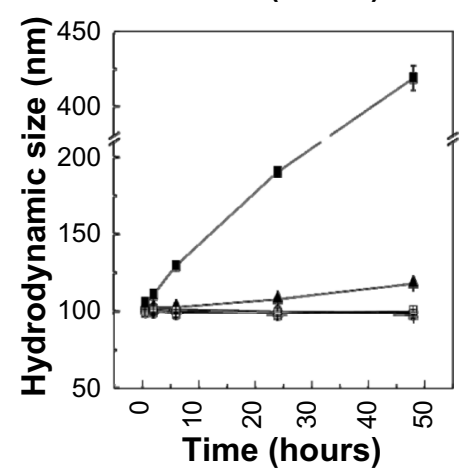

Figure 4 Zeta potential and hydrodynamic size of silica nanoparticles with L-histidine.

Notes: (A) Zeta potential of colloidal silica nanoparticles with $20 \mathrm{~nm}$ diameter, (B) hydrodynamic size of colloidal silica nanoparticles with 20 nm diameter, (C) zeta potential of colloidal silica nanoparticles with $100 \mathrm{~nm}$ diameter, and (D) hydrodynamic size of colloidal silica nanoparticles with $100 \mathrm{~nm}$ diameter at pH 5.5, 6.0, and 6.5, and pristine silica depending on the time, respectively. Open or solid squares/triangles/circles represent L-histidine coated or uncoated samples at pH 5.5, 6.0 , and 6.5 , respectively.

A

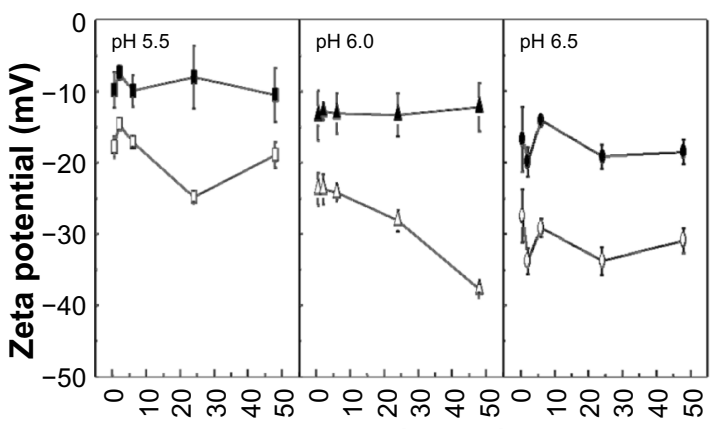$$
\text { C }
$$

Time (hours)

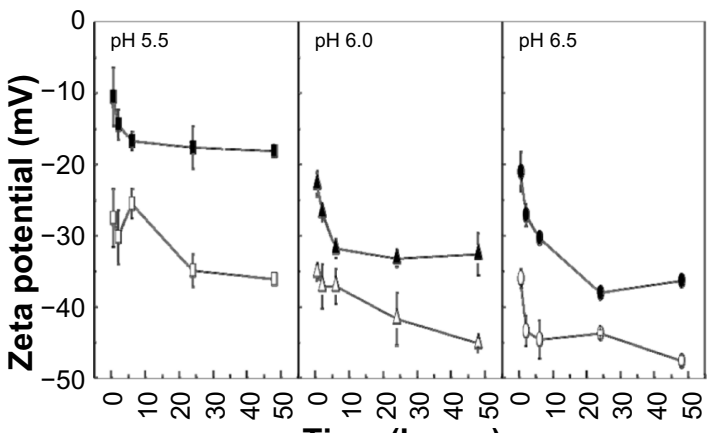

Time (hours)
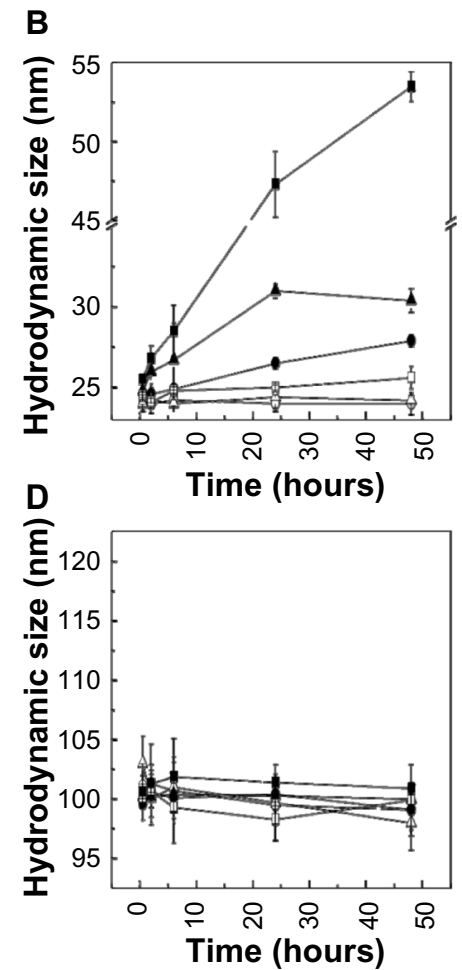

Figure 5 Zeta potential and hydrodynamic size of silica nanoparticles coated with L-arginine.

Notes: (A) Zeta potential of colloidal silica nanoparticles with $20 \mathrm{~nm}$ diameter, (B) hydrodynamic size of colloidal silica nanoparticles with $20 \mathrm{~nm}$ diameter, (C) zeta potential of colloidal silica nanoparticles with $100 \mathrm{~nm}$ diameter, and (D) hydrodynamic size of colloidal silica nanoparticles with $100 \mathrm{~nm}$ diameter at pH 5.5, 6.0 , and 6.5 , and pristine silica depending on the time, respectively. Open or solid squares/triangles/circles represent L-arginine coated or uncoated samples at pH 5.5, 6.0, and 6.5, respectively. 
exhibited clear zeta potential increases of approximately 10, 20, and $15 \mathrm{mV}$ upon L-arg coating. The hydrodynamic size showed a time dependent gradual increase. The final hydrodynamic sizes of $\mathrm{SiO}_{2}{ }^{\mathrm{EN} 20(-)}$ after 48 hours of L-arg coating were determined to be $27.9 \pm 0.4 \mathrm{~nm}, 30.4 \pm 0.7 \mathrm{~nm}$, and $53.5 \pm 0.9 \mathrm{~nm}$ for $\mathrm{pH} 6.5,6.0$, and 5.5, respectively. Although partial agglomeration of the $\mathrm{SiO}_{2}{ }^{\mathrm{EN} 20(\mathrm{R})}$ sample was observed, the degree of agglomeration was not significant compared with the $\mathrm{SiO}_{2}{ }^{\mathrm{EN} 20(\mathrm{H})}$, which showed 600-700 nm hydrodynamic sizes after 48 hours. The $100 \mathrm{~nm}$ colloidal silica also showed a zeta potential increase with the L-arg treatment. The zeta potential differences before and after coating were approximately $15 \mathrm{mV}$ at $\mathrm{pH} 5.5$ and approximately $10 \mathrm{mV}$ at $\mathrm{pH} 6.0$ and 6.5. $\mathrm{SiO}_{2}{ }^{\mathrm{EN} 100(-)}$ showed almost no change in hydrodynamic size during its 48 hour L-arg coating, suggesting high colloidal stability upon L-arg treatment.

To summarize the colloidal property change of colloidal silica nanoparticles upon amino acid coating, both the zeta potential and the hydrodynamic size exhibited characteristic changes according to the type of amino acids used. L-ser coating increased the zeta potential values of colloidal silica while the degree of change was sensitive to the $\mathrm{pH}$ condition. L-his was determined to be very effective in increasing the zeta potential values of colloidal silica at all the $\mathrm{pH}$ conditions tested. L-arg was also proven to be effective for zeta potential increases at the three aforementioned $\mathrm{pH}$ conditions, although its efficacy was slightly lower than that of L-his. Both $\mathrm{SiO}_{2}{ }^{\mathrm{EN} 20(-)}$ and $\mathrm{SiO}_{2}{ }^{\mathrm{EN} 100(-)}$ showed zeta potential change according to the amino acid coating and $\mathrm{pH}$ condition, and the effect of amino acids on the zeta potential increase was shown to be in the following order: L-his $>$ L-arg $>$ L-ser. The hydrodynamic size of colloidal silica was seriously affected by the L-his coating, showing a maximum approximately 30- and 4-fold size growth in $\mathrm{SiO}_{2}{ }^{\mathrm{EN} 20(-)}$ and $\mathrm{SiO}_{2}{ }^{\mathrm{EN} 100(-)}$, respectively. Both the L-ser and L-arg coatings were determined not to affect the hydrodynamic size of colloidal silica. The degree of hydrodynamic size change with respect to amino acid coating showed the following order: L-his $>$ L-arg $\approx$ L-ser. It was thus concluded that L-arg was the optimum amino acid coating agent in terms of zeta potential increase from highly negative to weakly negative values and colloidal stability without hydrodynamic size change.

\section{Colloidal stability evaluation with a turbidity test}

To evaluate in detail the colloidal stability of colloidal silica upon L-arg coating, the time dependent turbidity was measured utilizing the Turbiscan ${ }^{\mathrm{TM}}$ apparatus. ${ }^{34-39}$ Figure 6 shows the time dependent backscattering difference between the L-arg coated silicas and noncoated silicas at $\mathrm{pH}$ 5.5, 6.0,
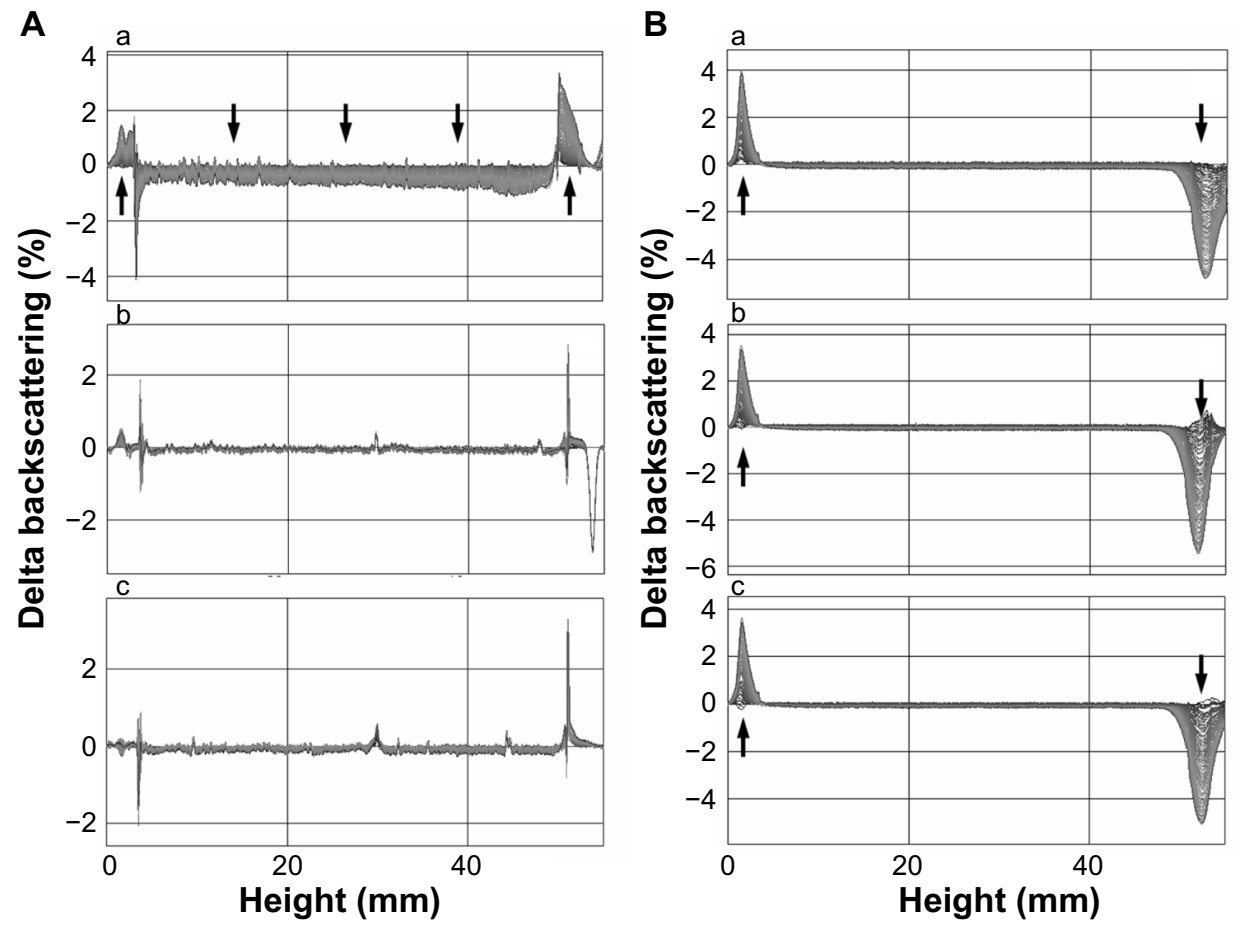

Figure 6 Time dependent turbidity of silica nanoparticles coated with L-arginine.

Notes: (A) Silica nanoparticles with $20 \mathrm{~nm}$ diameter and (B) hydrodynamic size of colloidal silica nanoparticles with $100 \mathrm{~nm}$ diameter at pH (a) 5.5, (b) 6.0, and (c) 6.5 depending on the time. The measurement data for 48 hours are represented by arrows. Gradations in color from dark grey ( 0 hours) to black ( 48 hours). 
and 6.5 for 48 hours. Turbiscan ${ }^{\mathrm{TM}}$ measured the backscattered light (near infrared), which was irradiated to the colloidal sample placed in a $55 \mathrm{~mm}$ tall vial containing a colloidal sample. The $\mathrm{x}$-axis of the graphs stands for the location where the backscattering occurred, and the y-axis indicates the difference between the backscattered light before and after coating. The measurements were carried out every 1.5 hours for 48 hours, and all the graphs were reflected on one sheet, with the changing pattern indicated with arrows in Figure 6. The $\mathrm{SiO}_{2}{ }^{\mathrm{EN} 20(\mathrm{R})}$ at $\mathrm{pH} 5.5$ showed an increase in backscattering in the lower (height: $0-5 \mathrm{~mm}$ ) and upper (height: $50-55 \mathrm{~mm}$ ) parts of the vial, and a decrease in backscattering in the middle part (height: 5-50 mm) of the vial (Figure 6A). Generally, the enhancement in backscattering is attributed to the increase in particle size or number resulting from flocculation or particle migration. Similarly, the decrease in backscattering is related to the reduced size or particle number. Therefore, it was considered that the $20 \mathrm{~nm}$ colloidal silica particles flocculated to a certain degree and migrated to a lower or higher position. These results corresponded well with the particle size increase of $\mathrm{SiO}_{2}{ }^{\mathrm{EN} 20(-)}$ after L-arg coating at $\mathrm{pH} 5.5$, which was measured by dynamic light scattering (Figure 5B). On the other hand, no significant backscattering change was observed in $\mathrm{SiO}_{2}{ }^{\mathrm{EN} 20(\mathrm{R})}$ at $\mathrm{pH} 6.0$ and 6.5, which indicates that the colloid was stably preserved under such coating conditions (Figure $6 \mathrm{~A}$ ). $\mathrm{SiO}_{2}{ }^{\mathrm{EN} 100(-)}$ showed a similar time dependent backscattering change pattern upon L-arg coating regardless of the $\mathrm{pH}$ condition. It exhibited a backscattering increase in the lower (height: $0-5 \mathrm{~mm}$ ) region and a decrease in the upper (height: $50-55 \mathrm{~mm}$ ) region at all the $\mathrm{pH}$ conditions tested while there was almost no change in backscattering in the middle region (height: $5-50 \mathrm{~mm}$ ) of the vial (arrows in Figure 6). These results signify possible sedimentation; however, the colloidal solution exhibited sufficient stability in accordance with previous reports. ${ }^{34-38}$

\section{Discussion}

The silica nanoparticles that were used in this study, $\mathrm{SiO}_{2}{ }^{\mathrm{EN} 20(-)}$ and $\mathrm{SiO}_{2}{ }^{\mathrm{EN} 100(-)}$, showed colloidal stability in water across a wide $\mathrm{pH}$ range ( $\mathrm{pH} 3-13)$, with a highly negative surface charge in terms of zeta potential (Figure 1). As the silica nanoparticles prepared in aqueous colloid contained an amorphous network of $\mathrm{SiO}_{4}$ tetrahedron inside and abundant $\mathrm{Si}-\mathrm{OH}$ groups at the outer surface, they were known to have highly negative surface charges. ${ }^{26}$ The purpose of this study was to prepare surface charge controlled silica nanoparticles for biological evaluation. Coating experiments were mainly carried out on as-purchased colloidal silica to change the highly negative surface charge of approximately $-40 \mathrm{mV}$ to weakly negative or partially positive values. Most of the selected coating reagents such as amine containing molecules, multivalent metal cation, and cationic polymers have cationic centers (Figure 2). Some of the zwitterionic amino acid molecules containing $-\mathrm{COO}^{-},-\mathrm{NH}_{3}^{+}$, and additional functional groups were also selected as potential coating agents. EDA and TAEA, which contained at least two amine sites, have been reported to introduce strong positive surface charges when treated on the nanoparticles. ${ }^{24,31,40,41}$ Thus, they were expected to shift the negative surface charge of silica to the positive direction by attaching one amine end to the nanoparticle and exposing the other end. APTES was considered to induce a positive surface charge by siloxane bonds to the silica surface and exposing amine ends. ${ }^{42}$ As expected, all the amine containing molecules showed strong interaction with the silica particles, but resulted in the formation of an interparticle network and consequently gelation (Table 1). Particle coagulation and the hydrodynamic size increase upon amine coating of the nanoparticles were also reported by Csőgör et al. ${ }^{24}$ EUDRAGIT $^{\circledR}$ E-100, an amine containing polymer, can also induce gelation as it has many amine moieties in one polymer chain. ${ }^{43}$

Surface charge control of silica utilizing multivalent metal cations was reported by Peng et al. ${ }^{30}$ They reported that trivalent $\mathrm{Al}^{3+}$ effectively changes the negative surface charges of silica particles to the positive region compared with the monovalent and divalent cations. In this study, the $\mathrm{Al}^{3+}$ treated colloidal silica nanoparticles showed immediate formation of an interparticle network and gelation. The current silica nanoparticles have a very small particle size (less than 100 $\mathrm{nm}$ ), but Peng et al utilized large silica samples with approximately $500 \mathrm{~nm}$ particle size. ${ }^{30}$ The relatively large surface area of the current silica nanoparticles, $\mathrm{SiO}_{2}{ }^{\mathrm{EN} 20(-)}$ and $\mathrm{SiO}_{2}{ }^{\mathrm{EN} 100(-)}$, facilitated the interaction between the particles and the coating agents, resulting in the destabilization of the colloids.

Amino acids, in the aspect of cationic charge density, are not considered effective coating materials as they retain the zwitterionic property in a wide range of $\mathrm{pH}$ values ( $\mathrm{pH} 4-8$ ), and only a few amino acids have basic functional groups. ${ }^{44}$ They have advantages, however, when the surface of the metal oxide or hydroxide nanoparticles are modified for biological assays. They are biologically endogenous substances, thus reducing the concerns regarding toxicity. Furthermore, carboxylates and amines can act as coordinating sites to metals, facilitating coating of the nanoparticles. Basic amino acids like L-his were reported for the positive charge modification of hydroxyapatite nanoparticles. ${ }^{45,46}$ 
The surface of an iron oxide nanoparticle was modified with glutamic acid and lysine through coordination bonding with carboxylate to control the surface charge while maintaining the particle size. ${ }^{29}$ In this study, one amino acid with an uncharged functional group, L-ser, and two amino acids with basic functional groups, L-his and L-arg, were utilized. The isoelectric points of L-ser, L-his, and L-arg are 5.68, 7.47, and 11.15, respectively. Especially, the imidazolium group $\left(\mathrm{pK}_{\mathrm{a}}\right.$ [an acid dissociation constant at logarithm scale] approximately 5.97) in L-his and the guanidinium group ( $\mathrm{pK}_{\mathrm{a}}$ approximately 13.2) in L-arg were expected to provide positive charges to the silica surfaces.

As shown in Figure 3, the L-ser coated silica nanoparticles showed an increase in zeta potential even though L-ser was in neutral zwitterionic form at $\mathrm{pH}$ 5.5-6.5. Some L-ser moieties can directly coordinate with the silicon atoms through the exposed carboxylate groups while much of the L-ser interacts via electrostatic interaction between the negative silica surface and the positive ammonium group (Figure 7). ${ }^{47}$ L-ser, however, does not have a strong cationic center, and thus, the zeta potential increase was quite limited. On the other hand, L-his and L-arg, which had additional cationic centers (imidazolium and guanidinium, respectively), showed clear zeta potential increases of $15-20 \mathrm{mV}$ in the $5.5-6.5 \mathrm{pH}$ range. The $\mathrm{pK}_{\mathrm{a}}$ values of imidazolium and guanidinium revealed that both amino acids had obvious positive charges at the above $\mathrm{pH}$ region, resulting in an increase in the zeta potential of the colloidal silica. The interaction between the positive centers of the coated amino acids with the neighboring silica particles, however, could be accelerated, giving rise to the formation of agglomeration or gelation, according to the coating conditions, such as the type of amino acid used for coating, the $\mathrm{pH}$, and the amount of coating materials used (Figure 4B and D, Table 1). Taking into account all the coating experiment results of the three amino acids, the optimal candidate, which showed not only a clear increase in zeta potential (difference of approximately $15 \mathrm{mV}$ ) but also colloidal stability, was L-arg.

Generally, the colloidal stability can be evaluated based on the high absolute value of the zeta potential or the inertness of the hydrodynamic size regardless of the time. It is also desirable, however, to investigate whether the colloid shows homogeneity change due to particle migration or interparticle interaction. ${ }^{34}$ Particle migration includes sedimentation and creaming while interparticle interaction stands for the change in particle size attributed to coalescence, flocculation, aggregation, or agglomeration. These phenomena can be precisely evaluated by measuring the time dependent turbidity change

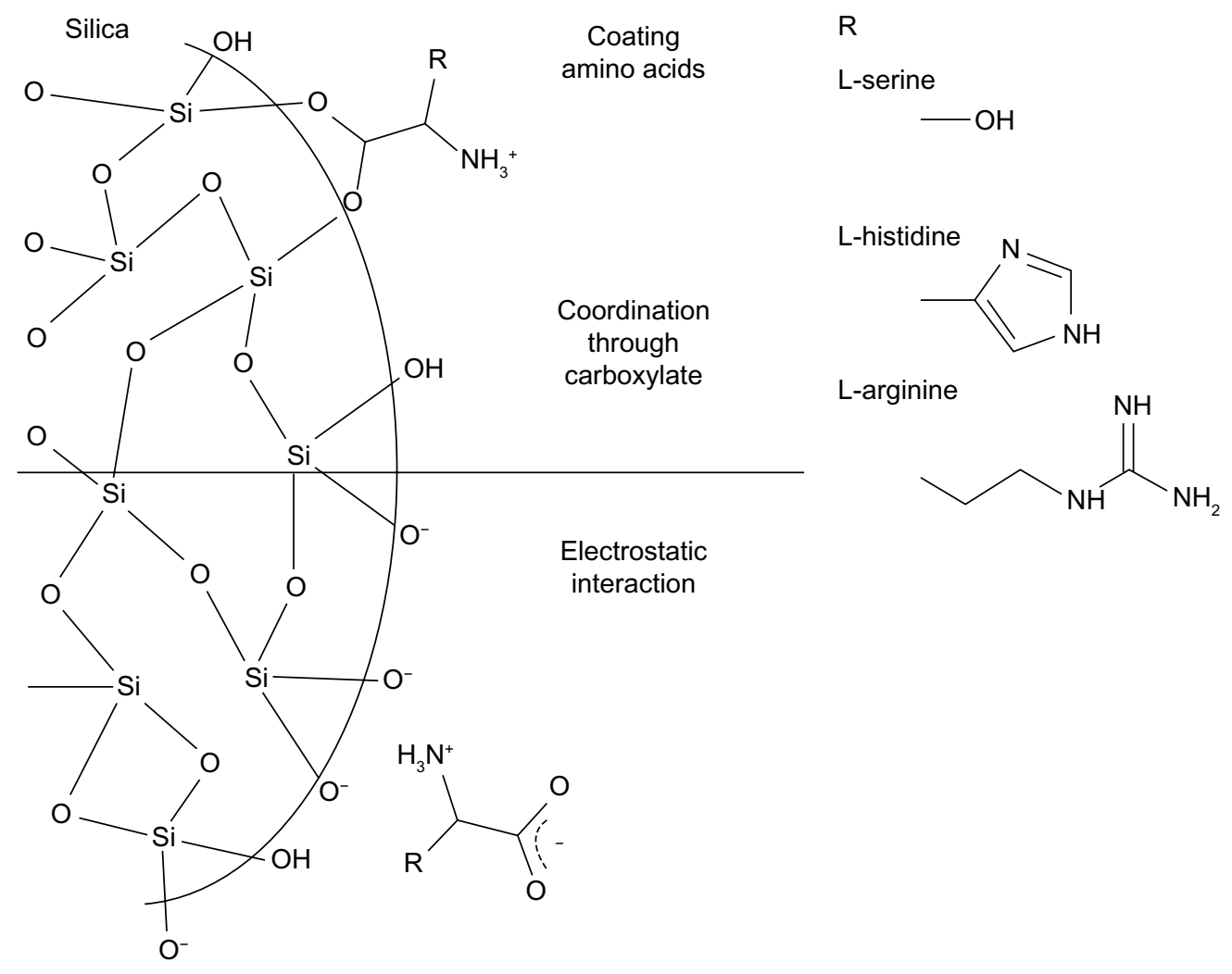

Figure 7 Suggested schematic illustration of the interaction between the silica nanoparticles and the amino acids. 
along the direction of gravity. Both $\mathrm{SiO}_{2}{ }^{\mathrm{EN} 20(-)}$ and $\mathrm{SiO}_{2}{ }^{\mathrm{EN} 100(-)}$ showed inertness in hydrodynamic size for 48 hours, but the absolute values of their zeta potentials were not sufficiently high to conclude that there was strong charge-charge repulsion between the silica nanoparticles. Thus, the colloidal stability was verified with the time dependent turbidity measurement, utilizing Turbiscan ${ }^{\mathrm{TM}}$ (Figure 6). As mentioned in the Results section, the $20 \mathrm{~nm}$ silica nanoparticles coated at $\mathrm{pH} 5.5$ exhibited slight coalescence, and those coated at $\mathrm{pH} 6.0$ and 6.5 were stable, which corresponded well with the hydrodynamic size results. The $100 \mathrm{~nm}$ silica nanoparticles did not show any significant size increase in the hydrodynamic size measurement, and the turbidity test did not show interparticle interaction. For the $100 \mathrm{~nm}$ diameter silica nanoparticles, however, a time dependent decrease in backscattering was observed in the upper part, and a time dependent increase in backscattering was observed in the lower part, which was attributed to sedimentation. The initial colloidal homogeneity, which is impeded due to sedimentation, can be recovered through a simple physical treatment, such as slow agitation. Thus, the $\mathrm{SiO}_{2}{ }^{\mathrm{EN100( \textrm {R } )}}$ did not have a colloidal stability problem.

\section{Conclusion}

In this study, the surface coating of colloidal silica with different particle sizes (20 nm and $100 \mathrm{~nm}$ ) with various cationic coating agents was demonstrated. The colloidal silica nanoparticles that were utilized in this study were determined to be highly negative in surface charge and stable in hydrodynamic size in a wide range of $\mathrm{pH}$ conditions. The surface charges of such silica nanoparticles can be modified using cationic molecules with amine groups or multivalent cations, but may give rise to agglomeration or networked gels due to high positive charge densities. Amino acids may be more biocompatible and have less toxicity concerns for modifying the surface charges of nanoparticles for biological studies. The $20 \mathrm{~nm}$ and $100 \mathrm{~nm}$ diameter colloidal silica nanoparticles showed clear zeta potential increases of approximately $15 \mathrm{mV}$ upon L-arg coating at $\mathrm{pH}$ 5.5-6.5 while the colloidal stability was maintained after coating for 48 hours. L-arg is therefore a potentially biocompatible candidate for modifying the surface charges of colloidal silica nanoparticles while maintaining colloidal stability.

\section{Acknowledgments}

This research was supported by a grant (10182MFDS991) from the Ministry of Food and Drug Safety in 2010-2013. This work was supported by the National Research Foundation of Korea (NRF) grant funded by the Korea government (MSIP) (2005-0049412) partly by the NRF of Korea (2010-0024370).

\section{Disclosure}

The authors report no conflicts of interest in this work.

\section{References}

1. Committee on Technology National Science and Technology Council. National Nanotechnology Initiative: Leading to the Next Industrial Revolution. A Report by Interagency Working Group on Nanoscience, Engineering and Technology. Washington: National Science and Technology Council Committee on Technology's Interagency Working Group on Nanoscience, Engineering and Technology; 2000. Available from: http://www.whitehouse.gov/files/documents/ostp/NSTC\%20 Reports/NNI2000.pdf. Accessed February 17, 2014.

2. Kim KM, Kang JH, Vinu A, Choy JH, Oh JM. Inorganic nanomedicines and their labeling for biological imaging. Curr Top Med Chem. 2013; 13:488-503.

3. Oh JM, Choi SJ, Lee GE, Han SH, Choy JH. Inorganic drug-delivery nanovehicle conjugated with cancer-cell-specific ligand. Adv Funct Mater. 2009;19(10):1617-1624.

4. Huang X, El-Sayed IH, Qian W, El-Sayed MA. Cancer cell imaging and photothermal therapy in the near-infrared region by using gold nanorods. J Am Chem Soc. 2006;128(6):2115-2120.

5. Reuveni T, Motiei M, Romman Z, Popovtzer A, Popovtzer R. Targeted gold nanoparticles enable molecular CT imaging of cancer: an in vivo study. Int J Nanomed. 2011;6:2859-2864.

6. Gupta AK, Gupta M. Synthesis and surface engineering of iron oxide nanoparticles for biomedical applications. Biomaterials. 2005;26(18): 3995-4021.

7. Patel D, Kell A, Simard B, et al. $\mathrm{Cu}^{2+}$-labeled, SPION loaded porous silica nanoparticles for cell labeling and multifunctional imaging probes. Biomaterials. 2010;31(10):2866-2873.

8. Liu Y, Yang Y, Zhang C. A concise review of magnetic resonance molecular imaging of tumor angiogenesis by targeting integrin $\alpha v \beta 3$ with magnetic probes. Int J Nanomed. 2013;8:1083-1093.

9. Wagner S, Schnorr J, Ludwig A, et al. Contrast-enhanced MR imaging of atherosclerosis using citrate-coated superparamagnetic iron oxide nanoparticles: calcifying microvesicles as imaging target for plaque characterization. Int J Nanomed. 2013;8:767-779.

10. Pumera M. Graphene-based nanomaterials for energy storage. Energ Environ Sci. 2011;4(3):668-674.

11. Linsebigler AL, Lu G, Yates JT. Photocatalysis on tio ${ }_{2}$ surfaces: principles, mechanisms, and selected results. Chem Rev. 1995;95(3): 735-758.

12. Koseki H, Asahara T, Shida T, et al. Clinical and histomorphometrical study on titanium dioxide-coated external fixation pins. Int J Nanomed. 2013;8:593-599.

13. Monticone S, Tufeu R, Kanaev AV. Complex nature of the UV and visible fluorescence of colloidal $\mathrm{ZnO}$ nanoparticles. $J$ Phys Chem $B$. 1998;102(16):2854-2862.

14. Lee SH, Pie JE, Kim YR, Lee HR, Son SW, Kim MK. Effects of zinc oxide nanoparticles on gene expression profile in human keratinocytes. Mol Cell Toxicol. 2012;8(2):113-118.

15. Zhu X, Jiang D, Tan S, Zhang Z. Improvement in the strut thickness of reticulated porous ceramics. J Am Ceram Soc. 2001;84(7):1654-1656.

16. Fueda Y, Matsumoto J, Shiragami T, Nobuhara K, Tasuda M. Porphyrin/ $\mathrm{MgCl}_{2} /$ silica gel composite as a cobalt-free humidity indicator. Chem Lett. 2007;36(10):1246-1247.

17. Choi JE, Park YH, Lee EY, et al. A safety assessment of phototoxicity and sensitization of $\mathrm{SiO}_{2}$ nanoparticles. Mol Cell Toxicol. 2011;7(2): 171-176.

18. Dekkers S, Krystek P, Peters RJ, et al. Presence and risks of nanosilica in food products. Nanotoxicology. 2011;5(3):393-405. 
19. Inter-Organization Programme for the Sound Management of Chemicals. Guidance on Sample Preparation and Dosimetry for the Safety Testing of Manufactured Nanomaterials. Paris: OECD; 2012. Available from: http://search.oecd.org/officialdocuments/ displaydocumentpdf $/$ ?cote $=$ env/jm/mono $\% 282012 \% 2940 \&$ doclangu age $=$ en. Accessed February 17, 2014.

20. Orts-Gil G, Natte K, Drescher D, et al. Characterisation of silica nanoparticles prior to in vitro studies: from primary particles to agglomerates. J Nanopart Res. 2011;13(4):1593-1604.

21. Graf C, Gao Q, Schütz I, et al. Surface functionalization of silica nanoparticles supports colloidal stability in physiological media and facilitates internalization in cells. Langmuir. 2012;28(20):7598-7613.

22. Orts-Gil G, Natte K, Thiermann R, et al. On the role of surface composition and curvature on biointerface formation and colloidal stability of nanoparticles in a protein-rich model system. Colloid Surface B. 2013; 108(0):110-119.

23. Natte K, Österle W, Friedrich JF, von Klitzing R, Orts-Gil G. Tuning interfacial properties and colloidal behavior of hybrid nanoparticles by controlling the polymer precursor. Macromol Chem Physic. 2012;213(22):2412-2419.

24. Csőgör Z, Nacken M, Sameti M, Lehr CM, Schmidt H. Modified silica particles for gene delivery. Mat Sci Eng C. 2003;23(1-2):93-97.

25. Kim YJ, Yu M, Park HO, Yang SI. Comparative study of cytotoxicity, oxidative stress and genotoxicity induced by silica nanomaterials in human neuronal cell line. Mol Cell Toxicol. 2010;6(4):336-343.

26. Kim KM, Kim HM, Choi MH, et al. Colloidal properties of surface coated colloidal silica nanoparticles in aqueous and physiological solutions. Sci Adv Mat. 2014;6(7):1573-1581.

27. Tang MX, Redemann CT, Szoka FC Jr. In vitro gene delivery by degraded polyamidoamine dendrimers. Bioconjugate Chem. 1996;7(6): 703-714.

28. Yang SR, Lee HJ, Kim JD. Histidine-conjugated poly(amino acid) derivatives for the novel endosomolytic delivery carrier of doxorubicin. $J$ Control Release. 2006;114(1):60-68.

29. Park JY, Choi ES, Baek MJ, Lee GH. Colloidal stability of amino acid coated magnetite nanoparticles in physiological fluid. Mater Lett. 2009;63(3-4):379-381.

30. Peng L, Qisui W, Xi L, Chaocan Z. Zeta-potentials and enthalpy changes in the process of electrostatic self-assembly of cations on silica surface. Power Technol. 2009;193(1):46-49.

31. Wang S, Song H, Ong WY, Han MY, Huang D. Positively charged and $\mathrm{pH}$ self-buffering quantum dots for efficient cellular uptake by charge mediation and monitoring cell membrane permeability. Nanotechnology. 2009;20(42):425102.

32. Shi Q, Su Y, Chen W, et al. Grafting short-chain amino acids onto membrane surfaces to resist protein fouling. J Membrane Sci. 2011;366(1-2): 398-404.

33. Kim KM, Kim TH, Kim HM, et al. Colloidal behaviors of $\mathrm{ZnO}$ nanoparticles in various aqueous media. Toxicol Environ Health Sci. 2012;4(2):121-131.
34. Mengual O, Meunier G, Cayre I, Puech K, Snabre P. Characterisation of instability of concentrated dispersions by a new optical analyser: the TURBISCAN MA 1000. Colloid Surface A. 1999;152(1-2): $111-123$.

35. Mengual O, Meunier G, Cayré I, Puech K, Snabre P. TURBISCAN MA 2000: multiple light scattering measurement for concentrated emulsion and suspension instability analysis. Talanta. 1999;50(2):445-456.

36. Lemarchand C, Couvreur P, Vauthier C, Costantini D, Gref R. Study of emulsion stabilization by graft copolymers using the optical analyzer Turbiscan. Int J Pharm. 2003;254(1):77-82.

37. Celia C, Trapasso E, Cosco D, Paolino D, Fresta M. Turbiscan lab expert analysis of the stability of ethosomes ${ }^{\circledR}$ and ultradeformable liposomes containing a bilayer fluidizing agent. Colloid Surface B Interfaces. 2009;72(1):155-160.

38. Liu J, Huang XF, Lu LJ, Li MX, Xu JC, Deng HP. Turbiscan Lab ${ }^{\circledR}$ Expert analysis of the biological demulsification of a water-in-oil emulsion by two biodemulsifiers. J Hazard Mater. 2011;190(1-3): 214-221.

39. Wiśniewska M, Terpiłowski K, Chibowski S, Urban T, Zarko VI, Gun'ko VM. Stability of colloidal silica modified by macromolecular polyacrylic acid (PAA) - application of turbidymetry method. $J$ Macromol Sci A. 2013;50(6):639-643.

40. Montes T, Grazu V, López-Gallego F, Hermoso JA, Guisan JM, Fernandez-Lafuente R. Chemical modification of protein surfaces to improve their reversible enzyme immobilization on ionic exchangers. Biomacromolecules. 2006;7(11):3052-3058.

41. Bhagiyalakshmi M, Yun LJ, Anuradha R, Jang T. Utilization of rice husk ash as silica source for the synthesis of mesoporous silicas and their application to $\mathrm{CO}_{2}$ adsorption through TREN/TEPA grafting. J Hazard Mater. 2010;175(1-3):928-938.

42. Cui Y, Wei Q, Park H, Leiber CM. Nanowire nanosensors for highly sensitive and selective detection of biological and chemical species. Science. 2001;293(5533):1289-1292.

43. Park JK, Choy YB, Oh JM, Kim JY, Hwang SJ, Choy JH. Controlled release of donepezil intercalated in smectite clays. Int J Pharm. 2008;359(1-2):198-204.

44. Berg JM, Tymoczko JL, Stryer L. Biochemistry. 7th ed. New York: WH Freeman and Company; 2012

45. Nara M, Torii H, Tasumi M. Correlation between the vibrational frequencies of the carboxylate group and the types of its coordination to a metal ion: an ab initio molecular orbital study. J Phys Chem. 1996;100(51):19812-19817.

46. Yang JH, Han YS, Park M, Park T, Hwang SJ, Choy JH. New inorganicbased drug delivery system of indole-3-acetic acid-layered metal hydroxide nanohybrids with controlled release rate. Chem Mater. 2007;19(10):2679-2685.

47. Spanos N, Klepetsanis PG, Koutsoukos PG. Model studies on the interaction of amino acids with biominerals: the effect of 1-serine at the hydroxyapatite-water interface. J Colloid Interf Sci. 2001;236(2):260-265.
International Journal of Nanomedicine

\section{Publish your work in this journal}

The International Journal of Nanomedicine is an international, peerreviewed journal focusing on the application of nanotechnology in diagnostics, therapeutics, and drug delivery systems throughout the biomedical field. This journal is indexed on PubMed Central, MedLine, CAS, SciSearch ${ }^{\circledR}$, Current Contents ${ }^{\circledR} /$ Clinical Medicine,
Dovepress

Journal Citation Reports/Science Edition, EMBase, Scopus and the Elsevier Bibliographic databases. The manuscript management system is completely online and includes a very quick and fair peer-review system, which is all easy to use. Visit http://www.dovepress.com/ testimonials.php to read real quotes from published authors. 